\title{
Regulation of Perineuronal Nets in the Adult Cortex by the Activity of the Cortical Network
}

\author{
${ }^{1}$ Gabrielle Devienne, ${ }^{1}$ Sandrine Picaud, ${ }^{1}$ Ivan Cohen, ${ }^{1}$ Juliette Piquet, ${ }^{1}$ Ludovic Tricoire, ${ }^{1}$ Damien Testa, ${ }^{2}$

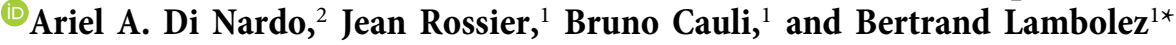 \\ ${ }^{1}$ Institut National de la Santé et de la Recherche Médicale, Centre National de la Recherche Scientifique, Neuroscience Paris Seine-Institut de \\ Biologie Paris Seine, Sorbonne Universités, Paris, 75005, France, and ${ }^{2}$ Centre for Interdisciplinary Research in Biology, Collège de France, Centre \\ National de la Recherche Scientifique, Unite Mixte de Recherche 7241, Institut National de la Santé et de la Recherche Médicale U1050, PSL \\ Research University, Paris, 75005, France
}

Perineuronal net (PNN) accumulation around parvalbumin-expressing (PV) inhibitory interneurons marks the closure of critical periods of high plasticity, whereas PNN removal reinstates juvenile plasticity in the adult cortex. Using targeted chemogenetic in vivo approaches in the adult mouse visual cortex, we found that transient inhibition of PV interneurons, through metabotropic or ionotropic chemogenetic tools, induced PNN regression. EEG recordings indicated that inhibition of PV interneurons did not elicit unbalanced network excitation. Likewise, inhibition of local excitatory neurons also induced PNN regression, whereas chemogenetic excitation of either PV or excitatory neurons did not reduce the PNN. We also observed that chemogenetically inhibited PV interneurons exhibited reduced PNN compared with their untransduced neighbors, and confirmed that single PV interneurons express multiple genes enabling individual regulation of their own PNN density. Our results indicate that PNN density is regulated in the adult cortex by local changes of network activity that can be triggered by modulation of PV interneurons. PNN regulation may provide adult cortical circuits with an activity-dependent mechanism to control their local remodeling.

Key words: cerebral cortex; critical period plasticity; extracellular matrix; fast-spiking parvalbumin interneurons; perineuronal net

\section{Significance Statement}

The perineuronal net is an extracellular matrix, which accumulates around individual parvalbumin-expressing inhibitory neurons during postnatal development, and is seen as a barrier that prevents plasticity of neuronal circuits in the adult cerebral cortex. We found that transiently inhibiting parvalbumin-expressing or excitatory cortical neurons triggers a local decrease of perineuronal net density. Our results indicate that perineuronal nets are regulated in the adult cortex depending on the activity of local microcircuits. These findings uncover an activity-dependent mechanism by which adult cortical circuits may locally control their plasticity.

\section{Introduction}

During the postnatal development of the cerebral cortex, the closure of a highly plastic period, called critical period, is

Received Mar. 2, 2021; revised Apr. 9, 2021; accepted Apr. 19, 2021.

Author contributions: B.L., G.D., I.C., L.T., A.A.D.N., J.R., and B.C. designed research; B.L., G.D., S.P., I.C., D.

T., A.A.D.N., J.R., and B.C. analyzed data; B.L. and G.D. wrote the first draft of the paper; B.L. wrote the paper;

G.D., S.P., J.P., D.T., and J.R. performed research; S.P., I.C., L.T., A.A.D.N., J.R., and B.C. edited the paper.

This work was supported by Agence Nationale de la Recherche, Grant/Award ANR-15-CE16-0010. The funder had no role in study design, data collection and analysis, decision to publish, or preparation of the manuscript. We thank Drs. Chris Magnus and Scott Sternson for the kind gift of chemogenetic PSAM-PSEM tools; the Allen Institute for sharing data and analysis tools; Drs. Maria Cecilia Angulo and Alberto Bacci for advice throughout this study; and Bernadette Hanesse and the IBPS Cell Imaging and Animal Facilities for their valuable help.

The authors declare no competing financial interests.

*Correspondence should be addressed to Bertrand Lambolez at bertrand.lambolez@upmc.fr.

https://doi.org/10.1523/JNEUROSCI.0434-21.2021

Copyright $\odot 2021$ the authors concomitant with the accumulation of the perineuronal net (PNN), a specialized extracellular matrix enwrapping fast-spiking parvalbumin (PV) interneurons (Hensch, 2005). The PNN is made of lecticans, proteoglycan link proteins, and tenascin $\mathrm{R}$, it is reticulated and attached to the membrane via hyaluronan, and it can be degraded by various proteases (Dityatev et al., 2010; Kwok et al., 2012; Ferrer-Ferrer and Dityatev, 2018). The PNN attracts in part the homeoprotein transcription factor OTX2 from cerebrospinal fluid to accumulate within PV cells, which in turn enhances PNN accumulation (Sugiyama et al., 2008). Enzymatic digestion of the PNN, modulating the inhibitory tone, or antagonizing OTX2 import by PV cells, reinstates high circuit plasticity in the adult; and a decrease of the PNN accompanies the reopening of plasticity, whatever the paradigm used (Hensch et al., 1998; Pizzorusso et al., 2002; Fagiolini et al., 2004; Harauzov et al., 2010; Sale et al., 2010; Beurdeley et al., 2012; 
Lensjø et al., 2017a). Conversely, PNN stability is linked to memory resilience, and PNN deficits are thought to contribute to circuit dysfunctions in several pathologies of the CNS (Testa et al., 2019).

Alteration of GABAergic transmission can induce PNN regression and reinstate high cortical plasticity, indicating that the PNN is dynamically regulated in the adult (Hensch, 2005; Harauzov et al., 2010; Sale et al., 2010). PV interneurons are strongly interconnected with excitatory pyramidal neurons, express multiple genes involved in PNN synthesis and degradation, and their maturation parallels that of their PNN (Angulo et al., 1999; Ascoli et al., 2008; Okaty et al., 2009; Rossier et al., 2015). This suggests that PV cells are key actors in the physiological regulation of the PNN. Likewise, transient and targeted inhibition of PV cells using chemogenetics (Alexander et al., 2009) in vivo is sufficient to restore visual plasticity in the mouse cortex after closure of the critical period (Kuhlman et al., 2013). We hypothesize that this chemogenetic paradigm induces PNN reduction, making the network permissive to circuit plasticity.

Here, we used targeted chemogenetic in vivo approaches to test this hypothesis and examine the physiological factors that govern PNN remodeling in the adult mouse visual cortex. We also assessed the acute electrophysiological effects of chemogenetic paradigms. We found that inhibiting PV interneurons, or local excitatory neurons, induced PNN regression, and obtained evidence for the regulation of PNNs individually.

\section{Materials and Methods}

Animals, viruses, and surgery. Experiments were conducted in accordance with the European Communities Council Directive 86/609/ 062 , and animal protocols approved by our local ethics committee (Ce5/ 2012/062). Transgenic mice lines from Jackson ImmunoResearch Laboratories are as follows: PV-Cre (\#008069, Pvalb ${ }^{\text {tml(cre)Arbr }}$ ) (Hippenmeyer et al., 2005) and Emx1-Cre (\#005628, Emx1 ${ }^{\mathrm{tml}(\mathrm{cre}) \mathrm{Krj}}$ ) (Gorski et al., 2002) were genotyped by PCR with following primers: $P V$-Cre, WT forward CAGAGCAGGCATGGTGACTA, WT reverse AGTACCAAGCAGGCAGGAGA, mutant forward, GCGGTCTGGCA GTAAAAACTATC, mutant reverse GTGAAACAGCATTGCTGTCA CTT (WT: $500 \mathrm{bp}$, mutant: $100 \mathrm{bp}$ ); Emx1 Cre, WT forward AAGGT GTGGTTCCAGAATCG, WT reverse CTCTCCACCAGAAGGCT GAG, mutant forward GCGGTCTGGCAGTAAAAACTATC, mutant reverse GTGAAACAGCATTGCTGTCACTT (WT: $102 \mathrm{bp}$, mutant: $378 \mathrm{bp})$.

Adeno-associated pseudovirions (AAVs) encoding designer receptor exclusively activated by designer drug (DREADD) (Alexander et al., 2009) AAV2/5-hSyn-DIO-hM4Di-mCherry (titer: $5.2 \times 10^{12} \mathrm{gc} / \mathrm{ml}$ ) and AAV2/5-hSyn-DIO-hM3Dq-mCherry $\left(7.8 \times 10^{12} \mathrm{gc} / \mathrm{ml}\right)$ were produced from Addgene plasmids \#44362 and \#44361 at the facility of Nantes University (Unite Mixte de Recherche 1089). AAV2/5-hsyn-FLEX:revPSAM $^{\mathrm{L} 141 \mathrm{~F}, \mathrm{Y} 115 \mathrm{~F}}$-GlyR-IRES-GFP $\left(3.6 \times 10^{12}\right.$, diluted at $\left.1 \times 10^{12} \mathrm{gc} / \mathrm{ml}\right)$ was generously provided by C.J. Magnus (Sternson Lab, Janelia Research Campus) (Magnus et al., 2011).
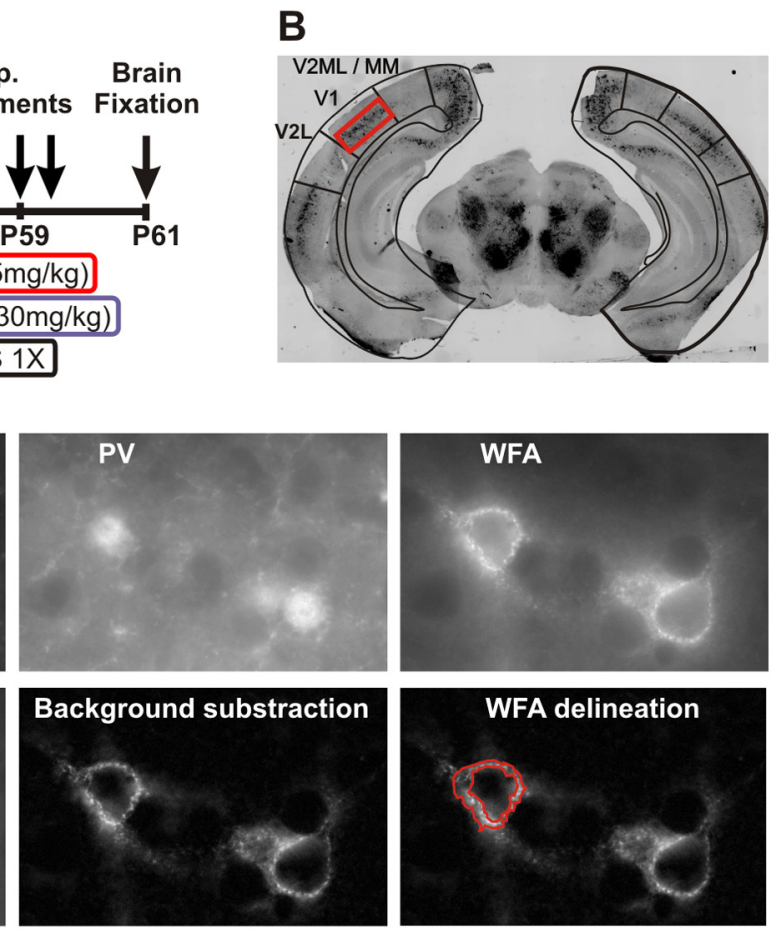

Figure 1. Chemogenetic paradigm and histologic analysis of PNN density in the V1 visual cortex. $\boldsymbol{A}$, Four weeks after hemilateral AAV injection in the V1 cortex, DREADD- or PSAM-GlyR-expressing mice received four injections of relevant agoa

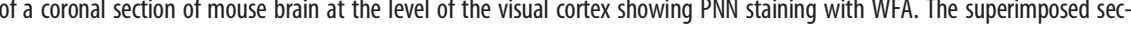
the mouse brain atlas delineates the densely stained V1 area flanked by V2L and V2ML areas exhibiting faint PNN PV and the chemogenetic tool, as exemplified here for the hM4Di-mCherry fusion protein. $\boldsymbol{D}$, In order to quantify tion of the ImageJ software (middle), and PNNs were delineated manually around the soma based on WFA staining intensity (right, red lines), to create ring-shaped ROIs using the XOR function of ImageJ. Scale bars: C, D, $20 \mu \mathrm{m}$.

For viral transduction, postnatal day (P) 25-28 PV-Cre or Emx1-Cre mice was anesthetized by intraperitoneal injection of ketamine/xylazine $(100 / 10 \mathrm{mg} / \mathrm{kg}$ body weight $)$ and restrained in a neonatal stereotaxic adaptor (David Kopf Instrument). The scalp was retracted, and a burr hole was drilled in the skull at coordinates $\mathrm{AP}=0.05 \mathrm{~mm}$ and $\mathrm{ML}=2$ $\mathrm{mm}$ from $\lambda$ to target the $\mathrm{V} 1$ area of the right visual cortex. Viral suspension $(0.5 \mu \mathrm{l}$ for hM3Dq and hM4Di, $1 \mu \mathrm{l}$ for PSAM-GlyR) was injected with a glass capillary $(1 \mu \mathrm{m}$ tip, Drummond) at $500 \mu \mathrm{m}$ below the pial surface at a speed of $100 \mathrm{nl} / \mathrm{min}$. The scalp was sutured and mice were housed for at least 4 weeks with food and water ad libitum.

Chemogenetic treatment and histologic processing. Four weeks after viral injection, DREADD-expressing mice received four intraperitoneal injections at $12 \mathrm{~h}$ intervals of DREADD agonist clozapine-N-oxide (CNO, $1 \mathrm{mg} / \mathrm{kg}$; HelloBio) or PBS (Na phosphate $10 \mathrm{~mm}, \mathrm{NaCl} 137 \mathrm{~mm}$, $\mathrm{KCl} 2.7 \mathrm{~mm}$, pH 7.4; $100 \mu \mathrm{l}$ ) (see Fig. 1). PSAM-GlyR-expressing mice were treated similarly with the PSAM agonist PSEM $^{89 S}(10 \mathrm{mg} / \mathrm{kg}$, kind gift of C.J. Magnus) (Magnus et al., 2011) or PBS.

One day after the last intraperitoneal injection, mice were anesthetized using a lethal mix of ketamine/xylazine $(200 / 20 \mathrm{mg} / \mathrm{kg}$ body weight) and perfused transcardially with PBS containing $4 \%$ PFA. Brains were extracted, incubated $2 \mathrm{~h}$ at $4^{\circ} \mathrm{C}$ in the same fixative, and sectioned in $50 \mu \mathrm{m}$ coronal slices using a vibratome (VT1000S, Leica Microsystems). Free-floating sections were blocked for $1.5 \mathrm{~h}$ at room temperature in $\mathrm{PBS} / 0.25 \%$ Triton $\mathrm{X}-100 / 0.2 \%$ gelatin solution (PBS-GT) and incubated overnight at $4^{\circ} \mathrm{C}$ in PBS-GT with primary antibodies against PV, and RFP (DREADD-mCherry) or GFP (PSAM-GlyR). Slices were then washed with PBS and incubated for $1.5 \mathrm{~h}$ at room temperature with relevant secondary antibodies in 
PBS-GT. After washing in PBS, slices were next incubated for $2 \mathrm{~h}$ with biotinylated Wisteria floribunda agglutinin (WFA, $10 \mu \mathrm{g} / \mathrm{ml}$, CliniSciences) for PNN labeling. Slices were then washed and incubated for $1.5 \mathrm{~h}$ with streptavidin-AMCA (1:1000, Vector Laboratories). Finally, slices were washed and mounted on gelatincoated slides in Fluoromount-G (Southern Biotechnology). Antibodies were used at following dilutions: mice IgG1 anti-PV (1:1000, Sigma Millipore), rat anti-RFP (1:500, Chromotek), chicken anti-GFP (1:1000, Aves Labs), goat anti-mouse IgG1 AlexaFluor488 (1:500, Invitrogen), goat anti-mouse IgG AlexaFluor-555 (1:500, Invitrogen), goat anti-rat IgG AlexaFluor-555 (1:500, Invitrogen), and donkey anti-chicken IgY AlexaFluor-488 (1:400; Jackson ImmunoResearch Laboratories).

Fluorescence images were acquired using an epifluorescence macroapotome (Axiozoomer, Carl Zeiss) equipped with filters DAPI, GFP, and CY3 to acquire images of entire sections, an epifluorescence microscope (DMR, Leica Microsystems) equipped with filters A4, GFP, and CY3 to analyze PNN density, and a laser scanning confocal microscope (SP5, Leica Microsystems) with $20 \times, 40 \times$, and $63 \times$ objectives, and 405 , 488 , and $561 \mathrm{~nm}$ lasers. Images were processed using ImageJ (National Institutes of Health; http://rsbweb.nih.gov/ij/).

PNN density analyses. PNN density was analyzed by quantifying WFA fluorescence intensity around PV-immunoreactive cells in the V1 area of both ipsilateral (virally transduced) and contralateral (uninjected) visual cortices using wide-field microscopy. Only brains showing extended viral transduction in V1 were kept for further analysis. In the case of targeted transduction of PV interneurons, only mCherry ${ }^{+}$ (DREADD-expressing) or GFP ${ }^{+}$(expressing PSAM-GlyR) cells were analyzed ipsilaterally. Analysis was performed on every second section of the adjacent $50 \mu \mathrm{m}$ coronal sections encompassing the bilateral V1 areas along the mediolateral and anteroposterior axes, resulting in 3 or 4 sections analyzed per animal. The region analyzed in V1 was selected using a $20 \times$ objective, based on conspicuously low WFA staining in V2 area (see Fig. 1) (Ueno et al., 2018), as delineated by Paxinos and Franklin (2004). Images were acquired in layers IV-V using a $63 \times$ objective, starting medially from the V2/V1 border and progressing laterally into V1 through contiguous acquisition fields. In each field, all $\mathrm{PV}^{+}$(or ipsilateral $\mathrm{PV}^{+} / \mathrm{mCherry}^{+}$or $\mathrm{PV}^{+} / \mathrm{GFP}^{+}$) cells were selected for PNN density analysis (see Fig. 1). Images were acquired with constant brightness and contrast, and variable exposure time. Perisomatic PNN was delineated manually based on WFA staining intensity (see Fig. 1), forming ringshaped ROIs defined using the XOR function of the FIJI software (ImageJ). For each ROI, we measured area and mean WFA fluorescence intensity, which was normalized for exposure time. For each animal, the average fluorescence intensity of contralateral ROIs was used to normalize fluorescence intensity of each ipsilateral and contralateral ROI. Data obtained in different mice for a given condition were compared using a KruskalWallis nonparametric test. Since no significant difference was observed between mice for a given condition, data were pooled. Between-group comparisons were performed using Mann-Whitney nonparametric test.

In order to investigate the regulation of the PNN by individual PV neurons, WFA staining intensity was compared within pairs of $\mathrm{PV}^{+}$cells: one being $\mathrm{hM}_{4} \mathrm{Di}^{+}\left(\right.$mCherry $\left.^{+}\right)$and the other being its closest $\mathrm{hM} 4 \mathrm{Di}^{-}$ $\left(\mathrm{mCherry}^{-}\right)$neighbor. Confocal images were acquired with a $40 \times$ objective at the lateral edge of the hM4Di-expressing zone within the V1 area, to maximize the number of $\mathrm{hM} 4 \mathrm{Di}^{+} / \mathrm{PV}^{+}$and $\mathrm{hM} 4 \mathrm{Di}^{-} / \mathrm{PV}^{+}$cell pairs. Pairs were selected based on a distance criterion: the mean of the minimal distance between $\mathrm{hM} 4 \mathrm{Di}^{+} / \mathrm{PV}^{+}$cells determined for each section (range: 70 $106 \mu \mathrm{m}, n=7$ sections, $N=3$ mice) was used as the maximal radius to select pairs of hM4Di ${ }^{+}$and $\mathrm{hM} 4 \mathrm{Di}^{-} \mathrm{PV}^{+}$neighboring cells. PNN density was quantified as described above, and compared within cell pairs. Comparison between $\mathrm{hM} 4 \mathrm{Di}^{+} / \mathrm{PV}^{+}$and $\mathrm{hM} 4 \mathrm{Di}^{-} / \mathrm{PV}^{+}$cells was performed using Wilcoxon nonparametric test. Linear regression analysis was performed to test the independence between WFA staining intensities of $\mathrm{hM} 4 \mathrm{Di}^{+} / \mathrm{PV}^{+}$ and $\mathrm{hM} 4 \mathrm{Di}^{-} / \mathrm{PV}^{+}$cells.

Electrophysiological recordings of CNO/DREADD effects in cortical slices. Four to 10 weeks after viral injection, mice were anesthetized using a lethal mix of ketamine/xylazine $(200 / 20 \mathrm{mg} / \mathrm{kg}$ body weight $)$ and $250-$ $\mu \mathrm{m}$-thick coronal slices of V1 visual cortex prepared for whole-cell patch- clamp recordings (Hay et al., 2019) performed on $\mathrm{mCherry}^{+}$layers IV-V $\mathrm{PV}$ interneurons or layer $\mathrm{V}$ pyramidal cells selected under epifluorescence illumination with a $535 \mathrm{~nm}$ LED (CoolLED) and an RFP filter set (Semrock). Membrane potentials were not corrected for liquid junction potential. Cells were set at $-60 \mathrm{mV}$ by continuous current injection and submitted to series of current pulses $(800 \mathrm{~ms}$, from -100 to $375 \mathrm{pA}$ with $25 \mathrm{pA}$ increments). Parameters were measured from three series of pulses in control conditions and $2 \mathrm{~min}$ after the beginning of CNO bath application. Resting potential was determined on sweeps where no current was injected, input resistance on responses to hyperpolarizing pulses eliciting $10-15 \mathrm{mV}$ shifts, and rheobase defined as the minimal depolarizing pulse triggering an action potential. Between-group comparisons were performed using paired Wilcoxon nonparametric test.

EEG recordings of CNO/DREADD effects in vivo. Four weeks after viral injection, mice were subjected to anesthesia induced with $2 \%$ isoflurane and maintained by ketamine/xylazine ( $100 / 10 \mathrm{mg}$ per kg body weight), and their body temperature maintained at $36.5^{\circ} \mathrm{C}$. Electrodes made of bundles of insulated tungsten wires were implanted through the skull and sealed in place with acrylic resin. An epidural screw placed above the olfactory bulb was used as ground. One electrode placed above the cerebellum was used as reference. Three recording electrodes were implanted ipsilateral to the hM4Di-expressing hemisphere in $\mathrm{V} 1(\mathrm{AP}=0.05 \mathrm{~mm}, \mathrm{ML}= \pm 2 \mathrm{~mm}, \mathrm{DV}=$ $-0.5 \mathrm{~mm}$ from $\lambda$ ) and somatosensory S1 (AP $=-2 \mathrm{~mm}, \mathrm{ML}=2 \mathrm{~mm}, \mathrm{DV}$ $=-0.5 \mathrm{~mm}$ from bregma) cortical areas. After a 1 week resting period, EEG and simultaneous video recordings of awake mice were performed as previously described (Sieu et al., 2015). A half hour recording was extracted in each condition for analysis using a custom-made software based on Labview (National Instruments). The EEG signal was filtered with 1-4, 6$10,30-50,55-95$, and $100-150 \mathrm{~Hz}$ pass-bands, and mean power values were extracted for each band and normalized to control condition. Equality of variances was assessed using the $F$ test. Data obtained in different conditions were compared using a Student's $t$ test.

Throughout this study, treatments (ligand vs PBS) or experimental conditions (transduction of PV-Cre or Emx1-Cre with DREADDs- or PSAM-encoding AAVs) were allocated randomly across mice, results are given as mean \pm SEM, and a $p$ value $<0.05$ was considered statistically significant.

Statistical analyses. Statistical analyses were performed using Statistica 6 software (Statsoft). Analyses have been performed using both mice genders. For each chemogenetics experiments, 3 or 4 mice per group (PBS or Drug) with between 70 and 130 cells per condition (Drug-WFA ipsi; Drug- WFA contra; PBS-WFA ipsi; PBS-WFA contra) have been analyzed. For EEG experiments, a total of 3 mice have been used. For the patch-clamp recordings, 8 cells per group (PBS or CNO) have been analyzed. All raw data are available on request to the corresponding author. All values are expressed as mean percentage \pm SEM percentage in Results and as mean \pm SEM in summary tables. Statistical significance for the chemogenetics experiments was determined using the Mann-Whitney $U$ test (Table 1). Comparisons between conditions (baseline, $\mathrm{CNO}$ ) of patch-clamp recordings were determined using a Wilcoxon nonparametric test (Table 2). Between-group comparisons of EEG band power were assessed using a Student's $t$ test (Table 3).

\section{Results}

\section{Targeted chemogenetic inhibition of PV interneurons} induces PNN regression in the adult visual cortex

The PNN accumulates postnatally to reach adult density at P50 in the V1 area of the mouse visual cortex (Lee et al., 2017; Lensjø et al., 2017b; Ye and Miao, 2013). In order to test the hypothesis that targeted chemogenetic inhibition of PV interneurons alters adult PNN density, we adapted the protocol known to reinstate visual plasticity at P35 (Kuhlman et al., 2013) to measure PNN changes between P58 and P61 (see Materials and Methods; Fig. 1). Hemilateral injection of Cre-dependent AAV encoding the inhibitory DREADD hM4Di fused to fluorescent protein mCherry in the $\mathrm{V} 1$ area of the visual cortex of $P V$-Cre mice resulted in robust and selective expression in PV interneurons, with virtually all 
Table 1. Summary of chemogenetic experimentsa

\begin{tabular}{|c|c|c|c|c|c|}
\hline \multirow[b]{2}{*}{ Mice } & \multirow[b]{2}{*}{ Virus } & \multicolumn{2}{|l|}{ Drug } & \multicolumn{2}{|l|}{ PBS } \\
\hline & & WFA ipsi & WFA contra & WFA ipsi & WFA contra \\
\hline \multirow[t]{2}{*}{ PV Cre } & hM4Di & $\begin{array}{l}0.397 \pm 0.044^{b} \\
\quad(N=3, n=70)\end{array}$ & $\begin{array}{l}1.000 \pm 0.080 \\
(n=72)\end{array}$ & $\begin{array}{l}1.011 \pm 0.085 \\
\quad(N=3, n=85)\end{array}$ & $\begin{array}{l}1.000 \pm 0.110 \\
(n=87)\end{array}$ \\
\hline & & \multicolumn{4}{|c|}{$\begin{array}{l}\text { Drug-ipsi }<\text { Drug-contra, } U_{(70,72)}=1001, p=0.000 ;{ }^{b} \text { Drug-ipsi }<\text { PBS-ipsi, } U_{(70,85)}=1219, p=0.012 ; b \text { PBS-ipsi vs PBS- } \\
\quad \text { contra, } U_{(85,87)}=3432, p=0.326\end{array}$} \\
\hline \multirow[t]{2}{*}{ PV Cre } & PSAM GlyR & $\begin{array}{l}0.510 \pm 0.046^{b} \\
\quad(N=3, n=110)\end{array}$ & $\begin{array}{l}1.000 \pm 0.050 \\
(n=119)\end{array}$ & $\begin{array}{l}1.051 \pm 0.072 \\
\quad(N=3, n=110)\end{array}$ & $\begin{array}{l}1.000 \pm 0.054 \\
(n=107)\end{array}$ \\
\hline & & \multicolumn{4}{|c|}{$\begin{array}{l}\text { Drug-ipsi }<\text { Drug-contra, } U_{(110,119)}=2742, p=0.000 ; \text { b Drug-ipsi }<\text { PBS-ipsi, } U_{(110,110)}=2866, p=0.000 ;{ }^{b} \text { PBS-ipsi vs } \\
\text { PBS-contra, } U_{(110,107)}=5723, p=0.726\end{array}$} \\
\hline \multirow[t]{2}{*}{ Emx1 Cre } & $\mathrm{hM} 4 \mathrm{Di}$ & $\begin{array}{l}0.689 \pm 0.049^{b} \\
\quad(N=4, n=122)\end{array}$ & $\begin{array}{c}1.000 \pm 0.049 \\
(n=130)\end{array}$ & $\begin{array}{l}1.027 \pm 0.061 \\
\quad(N=3, n=93)\end{array}$ & $\begin{array}{l}1.000 \pm 0.056 \\
(n=92)\end{array}$ \\
\hline & & \multicolumn{4}{|c|}{$\begin{array}{l}\text { Drug-ipsi }<\text { Drug-contra, } U_{(1230,122)}=4977, p=0.000 ;{ }^{b} \text { Drug-ipsi }<\text { PBS-ipsi, } U_{(93,122)}=3358, p=0.000 ;{ }^{b} \text { PBS-ipsi vs } \\
\quad \text { PBS-contra, } U_{(93,92)}=4227, p=0.888\end{array}$} \\
\hline \multirow[t]{2}{*}{ Emx1 Cre } & $\mathrm{hM} 3 \mathrm{Dq}$ & $\begin{array}{l}0.949 \pm 0.060 \\
\quad(N=3, n=101)\end{array}$ & $\begin{array}{c}1.000 \pm 0.059 \\
(n=101)\end{array}$ & $\begin{array}{l}0.950 \pm 0.043 \\
\quad(N=3, n=92)\end{array}$ & $\begin{array}{l}1.000 \pm 0.058 \\
(n=92)\end{array}$ \\
\hline & & \multicolumn{4}{|c|}{$\begin{array}{l}\text { Drug-ipsi vs Drug-contra, } U_{(101,101)}=4884, p=0.602 ; \text { Drug-ipsi vs PBS-ipsi, } U_{(92,101)}=4558, p=0.820 ; \text { PBS-ipsi vs PBS-con- } \\
\quad \text { tra, } U_{(92,92)}=4077, p=0.667\end{array}$} \\
\hline \multirow[t]{2}{*}{ PV Cre } & $\mathrm{hM} 3 \mathrm{Dq}$ & $\begin{array}{l}1.085 \pm 0.087 \\
\quad(N=3, n=86)\end{array}$ & $\begin{array}{l}1.000 \pm 0.074 \\
(n=90)\end{array}$ & $\begin{array}{l}1.114 \pm 0.079 \\
\quad(N=3, n=101)\end{array}$ & $\begin{array}{l}1.000 \pm 0.061 \\
(n=100)\end{array}$ \\
\hline & & \multicolumn{4}{|c|}{$\begin{array}{l}\text { Drug-ipsi vs Drug-contra, } U_{(90,86)}=3693, p=0.600 ; \text { Drug-ipsi vs PBS-ipsi, } U_{(86,101)}=4284, p=0.873 \text {; PBS-ipsi vs PBS-contra } \\
U_{(101,100)}=4902, p=0.719\end{array}$} \\
\hline
\end{tabular}

${ }^{a} N$ refers to number of animals, and $n$ to number of cells counted in each condition. Mann-Whitney $U$ test values and corresponding exact $p$ values are indicated.

${ }^{b}$ Significant difference.

Table 2. Statistical analysis of patch-clamp recordings ${ }^{a}$

\begin{tabular}{|c|c|c|c|c|}
\hline Mice & Virus & & $\begin{array}{l}\text { Control (before CN0 } 0.5 \\
\mu \mathrm{m} \text { application) }\end{array}$ & CNO $(0.5 \mu \mathrm{m})$ \\
\hline \multirow[t]{6}{*}{ PV Cre } & \multirow[t]{6}{*}{ hM4Di } & $V_{\mathrm{m}}(\mathrm{mV})$ & $-66.8 \pm 0.5$ & \multirow[t]{2}{*}{$-71.6 \pm 0.5$} \\
\hline & & $n=8$ & Control $<\mathrm{CNO}, t_{(8)}=2.52, p=0.012^{b}$ & \\
\hline & & $\mathrm{RI}(\mathrm{M} \Omega)$ & $152.9 \pm 13.6$ & \multirow[t]{2}{*}{$128.6 \pm 10.7$} \\
\hline & & $n=8$ & Control $>$ CN0, $t_{(8)}=2.52, p=0.012^{b}$ & \\
\hline & & Rheobase (pA) & $143 \pm 16$ & \multirow[t]{2}{*}{$191 \pm 23$} \\
\hline & & $n=8$ & Control $<\mathrm{CNO}, t_{(8)}=2.37, p=0.018^{b}$ & \\
\hline \multirow[t]{6}{*}{ Emx1 Cre } & hM3Dq & $\mathrm{Vm}(\mathrm{mV})$ & $-66.1 \pm 0.9$ & \multirow[t]{2}{*}{$-63.9 \pm 1.4$} \\
\hline & & $n=8$ & Control $>$ CN0, $t_{(8)}=2.38, p=0.018^{b}$ & \\
\hline & & $\mathrm{RI}(\mathrm{M} \Omega)$ & $139.8 \pm 12.5$ & \multirow[t]{2}{*}{$173.2 \pm 10.6$} \\
\hline & & $n=8$ & Control $<\mathrm{CNO}, t_{(8)}=2.10, p=0.036^{b}$ & \\
\hline & & Rheobase $(p A)$ & $60 \pm 3$ & \multirow[t]{2}{*}{$38 \pm 3$} \\
\hline & & $n=8$ & Control $>\mathrm{CN} 0, t_{(8)}=2.20, p=0.028^{b}$ & \\
\hline
\end{tabular}

${ }^{a} n$, number of cells; Wilcoxon Matched Pairs Test $t$ and exact $p$ values.

${ }^{b}$ Significant difference.

mCherry ${ }^{+}$cells being also $\mathrm{PV}^{+}(n=208$ of 208 cells; Fig. 2$)$. Four weeks after viral injection, mice were treated with the DREADD agonist CNO or with PBS. PNNs are most abundant at the peak of PV interneuron distribution in layer IV and upper layer V (Rudy et al., 2011; Ye and Miao, 2013; Lensjø et al., 2017b). We quantified PNN density around $\mathrm{PV}^{+}$cells in these layers using WFA staining (see Materials and Methods; Fig. 1). Following $\mathrm{CNO}$ treatment, the $\mathrm{PNN}$ of $\mathrm{hM} 4 \mathrm{Di}^{-} \mathrm{mCherry}^{+}$cells was strongly decreased compared with the PNN of the uninjected contralateral hemicortex $(39.7 \pm 4.4 \%$ of contralateral PNN density, $n=70$ mCherry ${ }^{+} / \mathrm{PV}^{+}$cells and $n=72$ contralateral $\mathrm{PV}^{+}$cells from 3 animals, $p<0.05$; Fig. 3; Table 1). Conversely, no significant change of the PNN of hM4Di ${ }^{-}$mCherry ${ }^{+}$cells was observed compared with contralateral PNN in PBS-treated animals $(101.1 \pm 8.5 \%$ of contralateral PNN density, $n=85$ mCherry $^{+}$cells and $n=87$ contralateral cells from 3 animals, $p=0.3$; Fig. 3 ; Table 1). The significantly lower PNN density of hM4Di ${ }^{+}$cells from CNO-treated animals compared with $\mathrm{hM}_{4} \mathrm{Di}^{+}$cells from PBS-treated animals (Table 1) is illustrated in Figure 3.
Table 3. Statistical analysis of EEG recordings ${ }^{a}$

\begin{tabular}{lcc}
\hline & PBS mice $(N=3)$ & CNO mice $(N=3)$ \\
\hline$\delta(1-4 \mathrm{~Hz})$ & $101.8 \pm 27.3$ & $100.1 \pm 16.9$ \\
& $t_{(3,3)} 0.09, p=0.93$ & \\
Theta $(6-10 \mathrm{~Hz})$ & $105.7 \pm 15.9$ & $56.3 \pm 22.3$ \\
& $t_{(3,3)}=3.12, p=0.035^{b}$ & \\
$\gamma$ low $(30-50 \mathrm{~Hz})$ & $91.9 \pm 16.1$ & $99.7 \pm 25.9$ \\
& $t_{(3,3)}=-0.45, p=0.68$ & \\
$\gamma$ mid $(55-95 \mathrm{~Hz})$ & $99.5 \pm 5.2$ & $58.7 \pm 8.4$ \\
& $t_{(3,3)}=7.18, p=0.002^{b}$ & \\
$\gamma$ high $(100-150 \mathrm{~Hz})$ & $94.9 \pm 4.1$ & $41.1 \pm 7.7$ \\
& $t_{(3,3)}=10.63, p=0.0002^{b}$ & \\
\hline
\end{tabular}

${ }^{a} N$, number of mice; Student's $t$ test and exact $p$ values.

${ }^{b}$ Significant difference.

These results indicate that activation by $\mathrm{CNO}$ of hM4Di expressed in PV interneurons locally induces PNN regression in the adult visual cortex.

The DREADD hM4Di is likely to inhibit GABA release from PV interneurons through effects at somatodendritic and axon terminal levels (Kruglikov and Rudy, 2008; Alexander et al., 2009; Stachniak et al., 2014), with a disinhibitory effect on network activities. Hence, PNN regression may result from moderate inhibition of PV interneurons leading to mild changes in network activity patterns, or from unbalanced network excitation because of marked disinhibition of excitatory neurons. To investigate these possibilities, we characterized acute electrophysiological effects of CNO in hM4Di-expressing mice.

\section{CNO treatment results in moderate inhibition of $\mathrm{hM} 4 \mathrm{Di}-$} expressing PV interneurons

We studied the effect of CNO (0.5 $\mu \mathrm{M})$ (Alexander et al., 2009) on the excitability of hM4Di-expressing PV interneurons using patch-clamp recordings in acute slices of visual cortex (see Materials and Methods). Expression of hM4Di did not conspicuously alter electrophysiological properties of PV interneurons in the absence of CNO (Cauli et al., 1997). CNO application 


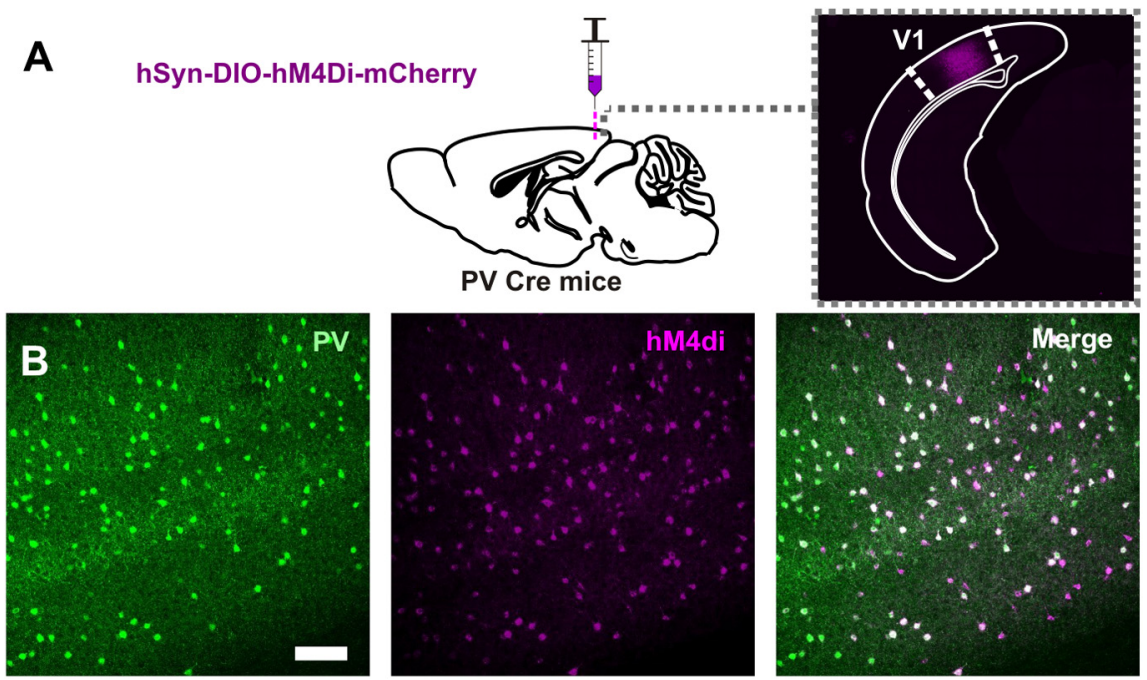

Figure 2. Targeted expression of DREADD hM4Di in PV interneurons. $\boldsymbol{A}$, Stereotaxic injection of Cre-dependent AAV encoding hM4Di fused to mCherry in the visual cortex of PV-Cre mice. Macrotome fluorescence picture showing expression of hM4Di$m$ Cherry revealed by anti-RFP immunohistochemistry 5 weeks after injection. The superimposed section of the mouse brain atlas represents the V1 area. $\boldsymbol{B}$, Confocal fluorescence images acquired in the V1 cortex after dual immunostaining showing hM4Di-mCherry expression in PV-positive cells. Scale bar, $100 \mu \mathrm{m}$.
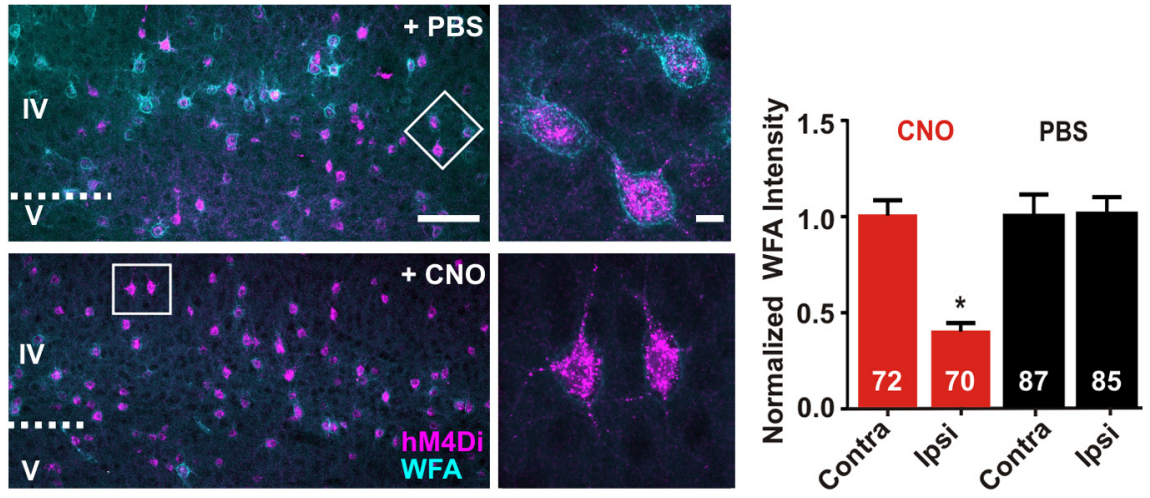

Figure 3. Targeted inhibition of PV interneurons using DREADD hM4Di induces PNN regression. Confocal fluorescence images acquired in the V1 cortex illustrate the PNN (WFA) surrounding hM4Di-expressing PV interneurons in layers IV-V after PBS or CNO treatment of the mice. Note the low PNN density around $\mathrm{hM}^{2} \mathrm{Di}^{+}$cells after $\mathrm{CNO}$ treatment, as exemplified in high-magnification images. Scale bars: left, $100 \mu \mathrm{m}$; right, $10 \mu \mathrm{m}$. Plot of PNN density around $\mathrm{PV}^{+}$(contralateral uninjected hemicortex) and $\mathrm{hM} \mathrm{Di}^{+}$/ $\mathrm{PV}^{+}$(ipsilateral injected) cells in the V1 cortex normalized for each mouse to mean density in contralateral hemicortex. Indicated in bars are the number of cells analyzed in 3 CNO-treated and 3 PBS-treated mice. *Significantly different from other conditions.

elicited a hyperpolarization (from $-66.8 \pm 0.5 \mathrm{mV}$ in control to $-71.6 \pm 0.5 \mathrm{mV}$ in $\mathrm{CNO}, p<0.05)$ and a decrease in input resistance (from $152.9 \pm 13.6 \mathrm{M} \Omega$ in control to $128.6 \pm 10.7 \mathrm{M} \Omega$ in CNO, $p<0.05, n=8$ PV cells; Fig. $4 A$; Table 2), as reported previously (Alexander et al., 2009). This effect was associated with an increase in rheobase (from $143 \pm 16 \mathrm{pA}$ in control to $191 \pm 23 \mathrm{pA}$ in CNO, $p<0.05$; Fig. $4 A$; Table 2). These results indicate that activation of hM4Di by $\mathrm{CNO}$ can inhibit PV neurons by decreasing their somatodendritic excitability. We next investigated acute $\mathrm{CNO}$ effects on network activities in V1 using EEG recordings in the hemicortex of awake mice expressing hM4Di in PV interneurons (see Materials and Methods). After $1 \mathrm{~h}$ baseline recording in control conditions, a first intraperitoneal injection of PBS was performed, followed $1 \mathrm{~h}$ later by intraperitoneal injection of CNO. We found no evidence for CNO-induced unbalanced excitation of the network indicative of marked disinhibition (Fig. 4B). CNO injection induced a strong decrease of network oscillations in the mid-high $\gamma$ frequency band (from $99.5 \pm 5.2 \%$ of control in PBS to $58.7 \pm 8.4 \%$ of control in $\mathrm{CNO}$ for the $55-95 \mathrm{~Hz}$ range, and from $94.9 \pm 4.1 \%$ of control in PBS to $41.1 \pm 7.7 \%$ of control in CNO for the $100-150 \mathrm{~Hz}$ range, $n=3$ mice, $p<0.05$; Fig. $4 B$; Table 3 ). We also observed a significant decrease in theta oscillations (from $105.7 \pm 15.9 \%$ of control in PBS to $56.3 \pm 22.3 \%$ of control in CNO, $p<0.05$; Fig. $4 B$; Table 3), but no change in lowfrequency $\gamma$ or $\delta$ oscillations. PV interneurons play a key role in synchronizing cortical neuronal populations, notably at $\gamma$ frequencies (Cardin et al., 2009). These results indicate that hM4Di activation by $\mathrm{CNO}$ induces moderate inhibition of PV cells associated with changes in network activity patterns in vivo, which could be the trigger of the observed PNN reduction.

Targeted excitation of glutamatergic neurons or PV interneurons does not alter adult PNN density

In order to explore disinhibition-induced network excitation as a cause of PNN regression, we selectively expressed the excitatory DREADD hM3Dq in either glutamatergic neurons or PV interneurons using the same paradigm as above in Emx1-Cre or PV-Cre mice, respectively (see Materials and Methods). We first verified that $\mathrm{CNO}(0.5 \mu \mathrm{M})$ enhanced the excitability of hM3Dq-expressing neurons using patch-clamp recordings of $\mathrm{hM}_{3 \mathrm{Dq}}{ }^{+}$layer $\mathrm{V}$ pyramidal cells $(n=8)$ in cortical slices. CNO elicited a depolarization (from $-66.1 \pm 0.9 \mathrm{mV}$ in control to $-63.9 \pm 1.4 \mathrm{mV}$ in $\mathrm{CNO}, p<0.05$; Fig. $5 A$; Table 2) and an increase in input resistance (from $139.8 \pm 12.5 \mathrm{M} \Omega$ in control to $173.2 \pm 10.6 \mathrm{~m} \Omega$ in $\mathrm{CNO}$, $p<0.05$; Fig. $5 A$; Table 2 ) of these neurons, accompanied by a decrease in rheobase (from $60 \pm 3 \mathrm{pA}$ in control to $38 \pm 3 \mathrm{pA}$ in $\mathrm{CNO}, p<0.05$; Fig. $5 A$; Table 2). These results confirm that $\mathrm{CNO}$ enhances the excitability of hM3Dq-expressing neurons.

We next probed the effect of in vivo activation of hM3Dqexpressing glutamatergic neurons in V1 on the PNN surrounding PV interneurons. Neither CNO nor PBS treatment significantly changed $\mathrm{PNN}$ density around $\mathrm{PV}^{+}$cells in the ipsilateral hM3Dq-expressing hemicortex compared with the uninjected contralateral hemicortex (Fig. 5B; Table 1). We also tested the effect of in vivo activation of hM3Dq-expressing PV interneurons in V1 on their PNN. Neither CNO nor PBS treatment significantly changed the density of the PNN around $\mathrm{hM} 3 \mathrm{Dq}^{+} / \mathrm{PV}^{+}$cells compared with contralateral $\mathrm{PV}^{+}$cells (Fig. 5C; Table 1). These results show that enhancing cortical network excitation does not trigger PNN regression in the adult, and suggest that $\mathrm{CNO}$-induced $\mathrm{PNN}$ regression around 
hM4Di ${ }^{+} \mathrm{PV}$ interneurons did not result from disinhibition-induced excitation of the cortical network.

Electrical silencing of PV interneurons triggers $\mathrm{PNN}$ regression in the adult visual cortex

The DREADD hM4Di is coupled to Gi intracellular signaling and thus results in both electrophysiological and metabotropic effects. In order to assess electrical silencing of PV interneurons as a trigger of PNN decrease, and rule out involvement of Gi-dependent metabotropic effects, we used an alternative chemogenetic tool, the chloride channel PSAM-GlyR exclusively activated by the agonist PSEM $^{89 S}$ (Magnus et al., 2011) coexpressed with GFP, to inhibit PV interneurons in the same paradigm as above (see Materials and Methods). We found that $82 \%$ of $\mathrm{GFP}^{+}$ cells were $\mathrm{PV}^{+}$( $n=75$ of 92 , not shown), consistent with efficient expression of PSAM-GlyR in PV interneurons. Following PSEM $^{89 S}$ treatment, the density of the PNN surrounding PSAM-GlyR-GFP ${ }^{+} / \mathrm{PV}^{+}$cells in layers IV-V was largely decreased as compared with the PNN of contralateral $\mathrm{PV}^{+}$cells $(51.0 \pm 4.6 \%$ of contralateral PNN density, $n=110 \mathrm{GFP}^{+}$cells and $n=119$ contralateral cells from 3 animals, $p<0.05$; Fig. 6; Table 1). PNN density around $\mathrm{GFP}^{+}$cells did not significantly differ from contralateral PNN in PBS-treated animals (Fig. 6; Table 1). These results indicate that PNN regression in the adult visual cortex can be triggered by electrical silencing of PV interneurons.

We next reasoned that PV interneuron silencing can, in principle, also be achieved by decreasing their synaptic excitation. We thus targeted expression of hM4Di to inhibit excitatory neurons in the V1 area. $\mathrm{CNO}$ treatment significantly reduced the PNN of $\mathrm{PV}^{+}$cells in the ipsilateral hM4Di-expressing hemicortex compared with contralateral PNN $(68.9 \pm 4.9 \%$ of contralateral PNN density, $n=122$ ipsilateral and $n=130$ contralateral $\mathrm{PV}^{+}$ cells from 4 animals, $p<0.05$; Fig. 7; Table 1). PBS treatment had no significant effect on PNN density (Fig. 7; Table 1). These data indicate that a decrease in cortical network excitation induces PNN regression in the adult visual cortex, and are consistent with the hypothesis that PV interneuron activity may play a key role in this process.

Our results collectively suggest that PNN density is regulated in the adult cortex by network activity changes that can be triggered by modulating the electrical activity of PV interneurons.

The PNN around each PV interneuron may be regulated individually

During histochemical analyses of CNO-treated mice, we noticed that $\mathrm{hM}_{4} \mathrm{Di}^{-} \mathrm{PV}$ interneurons had dense PNNs, whereas the

B
A Control + CNO
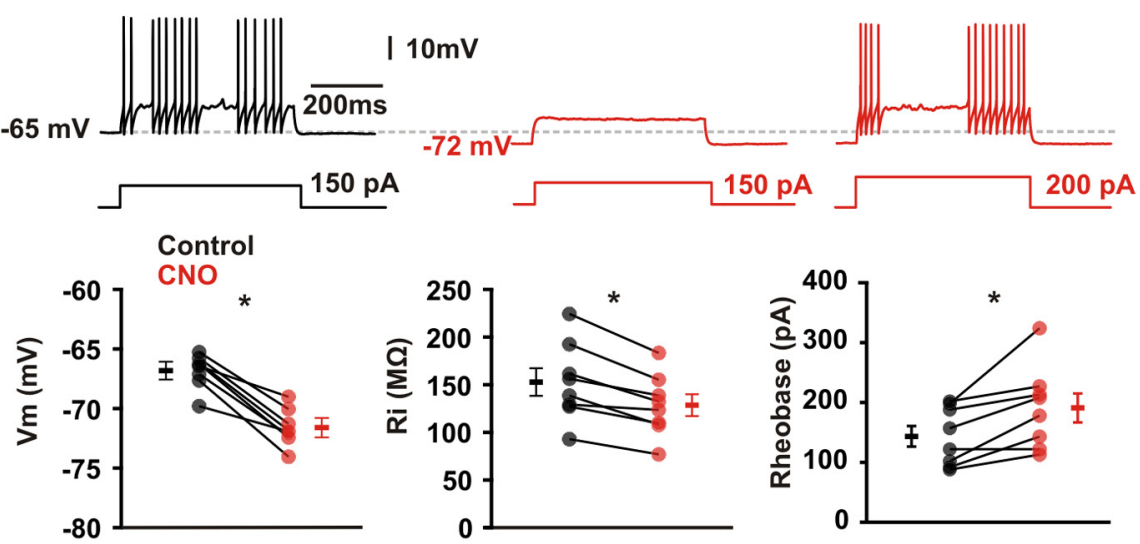

Baseline

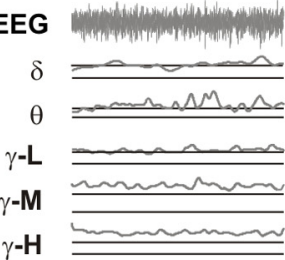

PBS

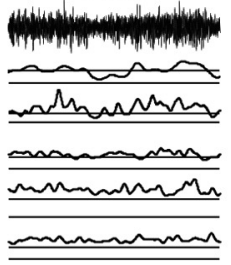

CNO

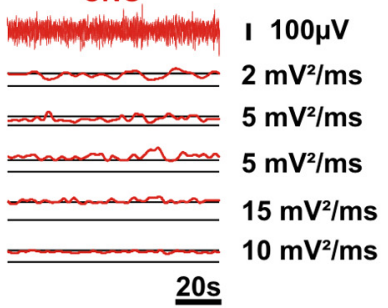

20s

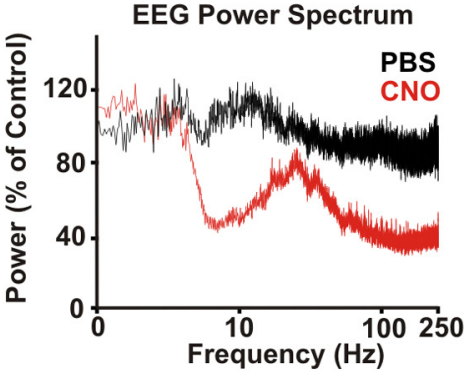

EEG Frequency Band Power

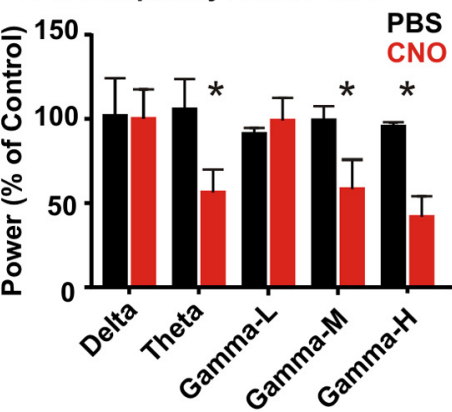

Figure 4. CNO decreases the excitability of hM4Di-expressing PV interneurons and reduces cortical $\gamma$ oscillations. $\boldsymbol{A}$, Patch-clamp recordings in cortical slices. Traces represent responses of a hM4Di-expressing interneuron to depolarizing current step in control condirent needed to induce action potential firing. Plots represent parameters measured in hM4Di-expressing interneurons $(n=8)$. Note the cortex of awake PV-Cre mouse before and after consecutive intraperitoneal injections of PBS and CNO. The EEG signal was filtered to analyze osillations in the $\delta 1-4 \mathrm{~Hz}$, theta $6-10 \mathrm{~Hz}, \gamma$ low $30-50 \mathrm{~Hz}, \gamma$ mid $55-95 \mathrm{~Hz}$, and $\gamma$ high $100-150 \mathrm{~Hz}$ frequency ranges. Traces represent samples obtained from 1 mouse. Graphs represent mean results from 3 mice. *Significant differences.

PNN of neighboring hM4Di ${ }^{+}$cells was reduced (for examples, see Fig. $8 A$ ). This suggests that the PNN around each PV interneuron is regulated individually. In order to test this hypothesis, we compared PNN density within pairs of hM4Di ${ }^{+}$and hM4Di ${ }^{-}$ PV interneuron neighbors located at short distance from each other in the V1 area (maximal distance $106 \mu \mathrm{m}$; see Materials and Methods; Fig. 8B). We verified that PNN density around $\mathrm{hM} 4 \mathrm{Di}^{-}$cells was higher than around hM4Di ${ }^{+}$cells (WFA staining intensity $85.1 \pm 5.5 \%$ of $\mathrm{hM}_{4} \mathrm{Di}^{-}$cells, $n=21$ cell pairs from 3 animals; Fig. 8B). We next plotted WFA staining intensity of $\mathrm{hM} 4 \mathrm{Di}^{-}$cells against that of $\mathrm{hM}_{4} \mathrm{Di}^{+}$cells for each PV interneuron pair (Fig. 8B). The plot was skewed toward higher WFA staining around $\mathrm{hM} 4 \mathrm{Di}^{-}$cells, consistent with hM4Di effect on the PNN. Linear regression analysis yielded a slope of 0.2 , which did not significantly differ from the zero slope value expected from independence between WFA staining intensities of 
A

Control

+ CNO
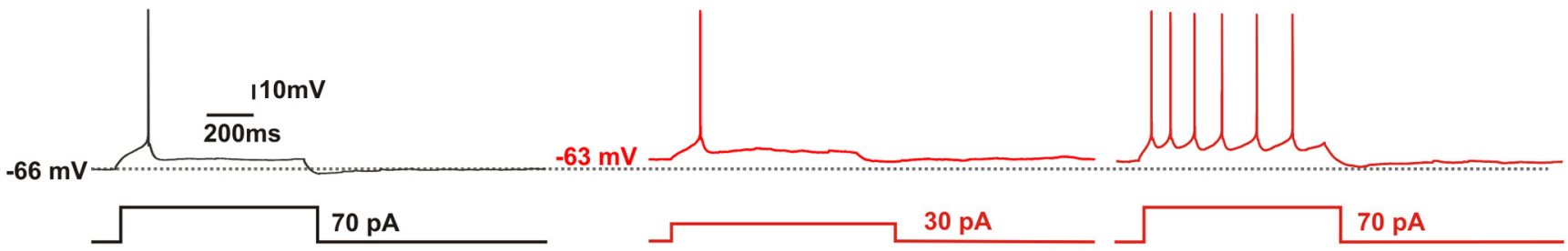

Control

CNO
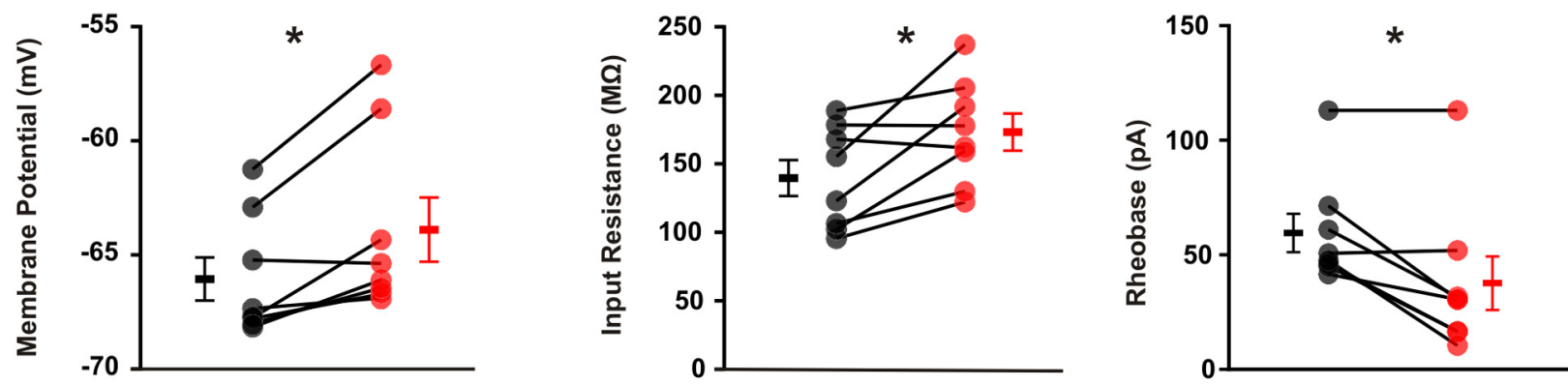

B
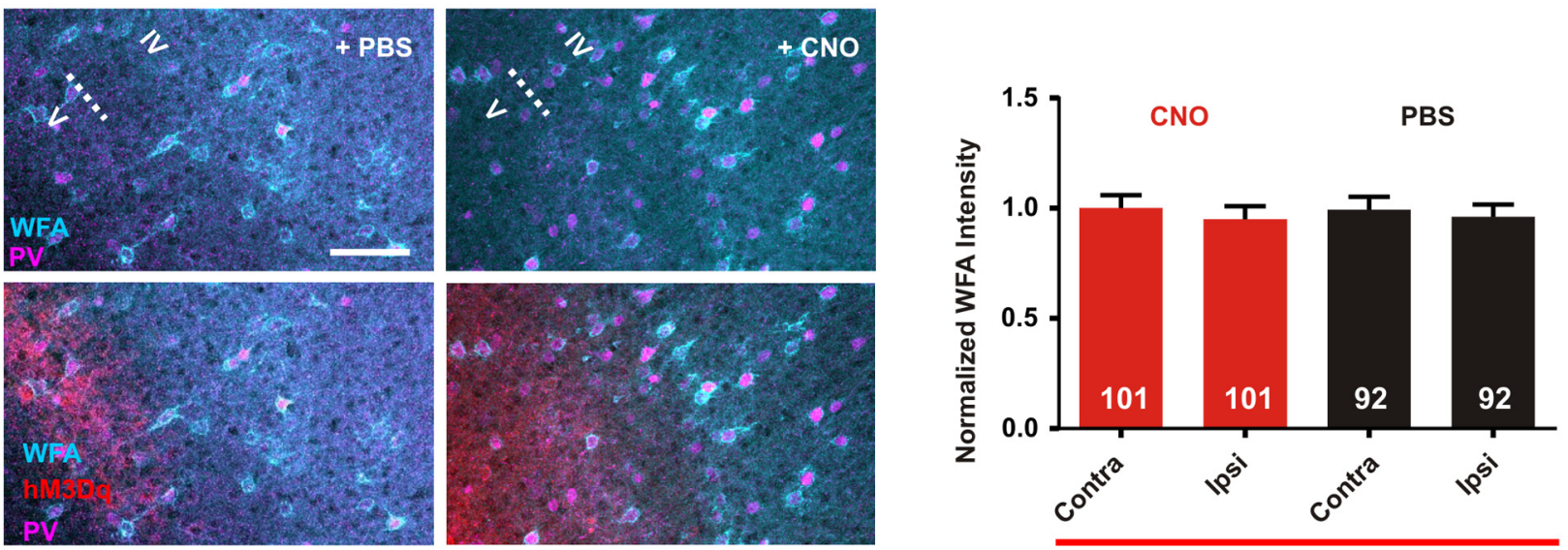

C
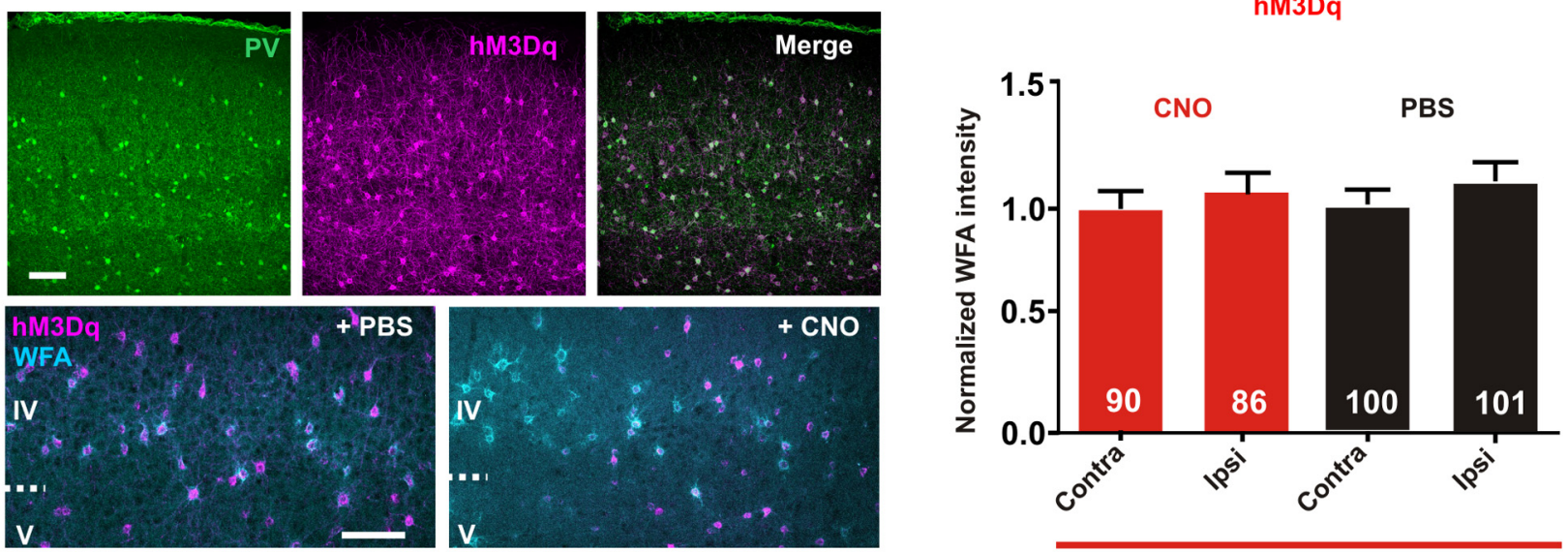

hM3Dq

Figure 5. Targeted excitation of glutamatergic or PV neurons using hM3Dq does not alter PNN density. A, Patch-clamp recordings in cortical slices. Traces represent responses of an hM3Dq-expressing layer V pyramidal neuron to depolarizing current steps in control conditions and on bath application of CNO (0.5 $\mu \mathrm{M})$. CNO application elicited a depolarization of the membrane potential and a decrease of the current needed to induce action potential firing. Plots represent electrophysiological parameters measured in control and CNO conditions in hM3Dq-expressing neurons ( $n=8$ ). *Significant differences. $\boldsymbol{B}$, Confocal fluorescence images illustrate the PNN (WFA) surrounding PV ${ }^{+}$cells in the vicinity of hM3Dq-expressing excitatory neurons in layers IV-V of the V1 cortex of mice treated with PBS or CNO. For better visualization, top panels represent WFA and anti-PV labeling separately from hM3Dq-mCherry-positive excitatory neurons visible on bottom panels. Scale bar, $100 \mu \mathrm{m}$. Plot of PNN density around $\mathrm{PV}^{+}$cells ipsilateral and contralateral to hM3Dq expression in the V1 cortex normalized for each mouse to mean density in contralateral hemicortex. Indicated in bars are the number of cells 


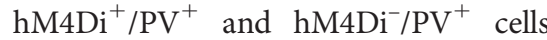
$(p=0.12)$. These results suggest that PNN density around each PV interneuron is regulated independently of that of its PV cell neighbors.

PV interneurons express multiple genes involved in synthesis and degradation of the PNN (Okaty et al., 2009; Rossier et al., 2015). We thus searched through published transcriptomic database of single cells collected from the primary visual cortex of P56 mice (Tasic et al., 2018) for the expression of genes that may enable individual cortical neural cells to contribute to the local regulation of individual PNN density. Figure $8 C$ shows expression levels of selected PNN lecticans, linkers, and proteases in 10,100 cells comprising major interneuron and layers II-V excitatory neuron types as previously defined (Tasic et al., 2018), as well as astrocytes. The expression profiles of PNN-related genes differed between cell types, with the largest array of genes expressed by PV interneurons. Strikingly, all lecticans and PNN linker mRNAs were present in PV interneurons, which preferentially express Acan and weakly express Ptprz1 mainly found in astrocytes (Maurel et al., 1994; Rossier et al., 2015). PV interneurons strikingly differed from other cell types in expressing significant levels of all tested proteases, except Mmp9 mainly observed in a subtype of layer $\mathrm{V}$ excitatory neurons. Notably, secreted proteases were preferentially expressed by PV interneurons consistent with earlier observations (Rossier et al., 2015). These results confirm that, among cortical cell types, adult PV interneurons express the largest set of key genes enabling individual cells to regulate locally the accumulation and degradation of the PNN.

\section{Discussion}

We tested the effects of targeted chemogenetic modulation of PV interneurons and excitatory neurons on PNN density around PV interneurons in the adult visual cortex. Inhibition of PV interneurons using the Gi-coupled hM4Di or the chloride channel PSAMGlyR, as well as inhibition of glutamatergic neurons, induced PNN regression. Inhibition of PV interneurons did not elicit unbalanced excitation of the network and excitation of glutamatergic neurons or of PV interneurons did not alter PNN density, suggesting that

$\leftarrow$

analyzed in 3 CNO-treated and 3 PBS-treated mice. C, Top confocal fluorescence images represent hM3Dq-mCherry expression in $\mathrm{PV}^{+}$cells of the V1 cortex 5 weeks after injection of corresponding Cre-dependent AAV in a PV-Cre mouse. Bottom confocal fluorescence images represent the PNN (WFA) surrounding $\mathrm{hM} 3 \mathrm{Dq}^{+} \mathrm{PV}$ interneurons in layers IV-V after PBS or CNO treatment of the mice. Scale bars, $100 \mu \mathrm{m}$. Plot of PNN density around $\mathrm{PV}^{+}$(contralateral uninjected hemicortex) and $\mathrm{hM}_{3} \mathrm{Dq}^{+} / \mathrm{PV}^{+}$(ipsilateral injected) cells. Indicated in bars are the number of cells analyzed in 3 CNO-treated and 3 PBS-treated mice. disinhibition-induced network excitation was not the cause of PNN regression. We also found that the PNN of hM4Di-expressing PV cells was reduced compared with the PNN of their hM4Di- neighbors, and that PV interneurons express genes enabling control of their own PNN density. Our results indicate that a decreased activity of PV interneurons, and resulting changes in network activity, can trigger PNN regression locally in the adult cortex, and suggest that individual PV cells can contribute to the regulation of their own PNN.

\section{Targeted chemogenetic modulation of PV interneurons or excitatory neurons}

Cre-dependent viral transduction resulted in robust and selective expression of chemogenetic actuators, consistent with previous studies (Gorski et al., 2002; Hippenmeyer et al., 2005; Alexander et al., 2009; Krashes et al., 2011; Magnus et al., 2011). Cell typespecific targeting was assessed by immunochemistry and patchclamp recordings of transduced neurons, which all exhibited electrophysiological properties typical of PV interneurons or glutamatergic neurons (Connors and Gutnick, 1990; Cauli et al., 1997). Our results exclude DREADD-independent effects of 


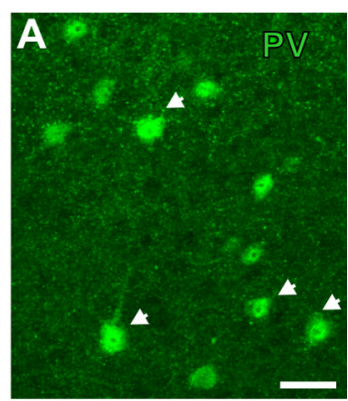

B PNN analysis of closest neighbors

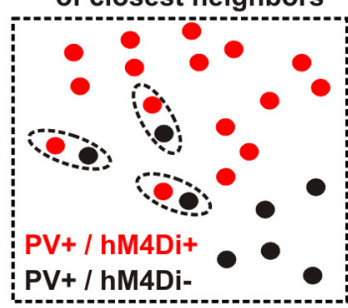

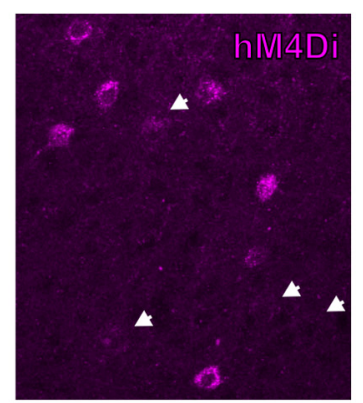
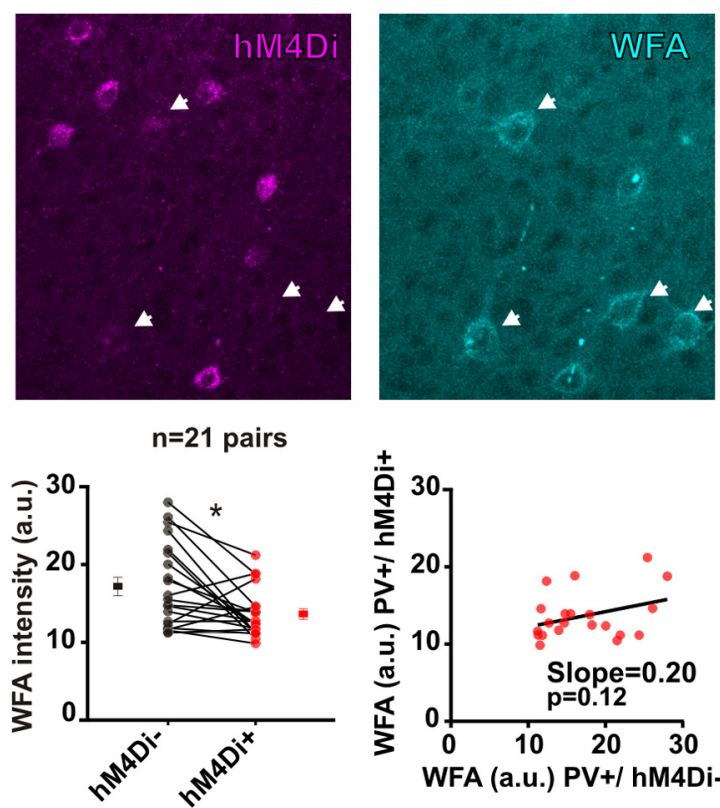

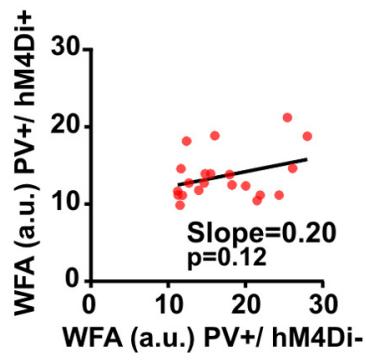

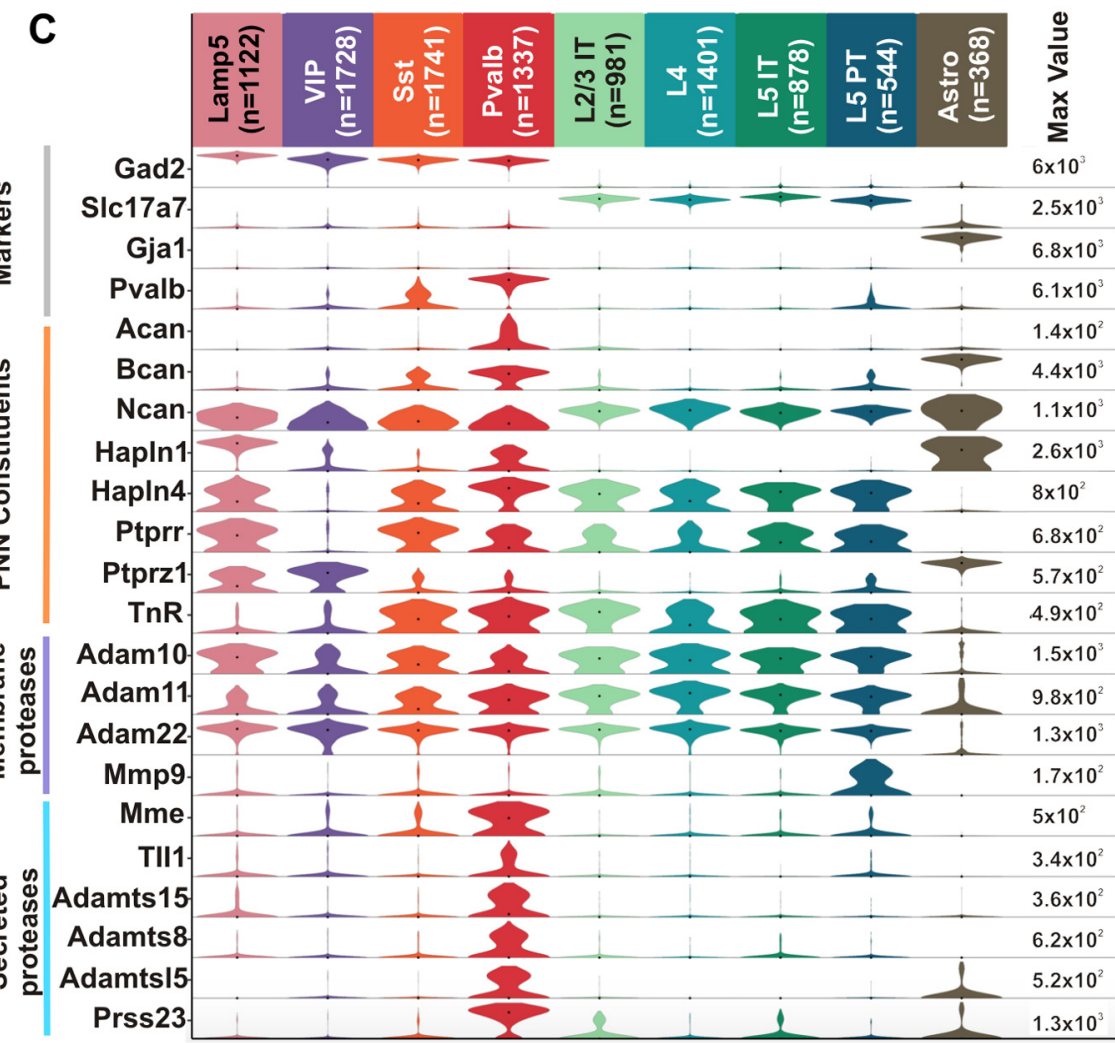

Figure 8. The PNN around each PV interneuron may be regulated individually. $\boldsymbol{A}$, Examples of the high PNN density (arrows) observed around $\mathrm{hM} \mathrm{Di}^{-}$, or weakly $\mathrm{hM} \mathrm{Di}^{+} \mathrm{PV}$ interneurons compared with the low PNN density observed around their $\mathrm{PV}^{+}$neighbors robustly expressing hM4Di in the V1 cortex of a CN0-treated mouse. Scale bar, $20 \mu \mathrm{m}$. B, Comparison of PNN density within pairs of $\mathrm{hM} \mathrm{Di}^{+}$and $\mathrm{hM} \mathrm{DDi}^{-}$closest neighbors $\mathrm{PV}^{+}$cells: selection criterion (left), individual and mean WFA intensity (middle, *significant difference), and scatter plot of WFA intensity for PV interneuron pairs (right, $n=21$ ). The slope of linear regression did not significantly differ from zero. C, Violin plots showing distributions of individual gene expression in 10,100 single cells from primary visual cortex of P56 mice. Data are from the Allen Institute. Cells are from subclasses segregated in Tasic et al. (2018) (20): GABAergic (Lamp5, Vip, Sst, and Pvalb), glutamatergic (layers 2/3 and 5 IT intratelencephalic, layer 4, layer 5 PT pyramidal tract) and astrocytes. Rows represent individual gene expression across cell types. Values (number per million reads) are displayed on a $\log 10$ scale normalized to maximum expression value for each gene (right column). Black dots represent median values. Markers: Gad2, glutamate decarboxylase; SIc17a7, vesicular glutamate transporter; Gja1, gap junction alpha1; Pvalb, PV. Lecticans: Acan, aggrecan; Bcan, brevican; Ncan, neurocan. PNN linkers: Hapln, hyaluronan and proteoglycan link protein; Ptprr and Ptprz1, Protein Tyrosine Phosphatase Receptor types $R$ and Z1; Tnr, tenascin R. Proteases: Adam, A Disintegrin And Metalloproteases; Mmp9, membrane metallopeptidase 9; Mme,
CNO (Gomez et al., 2017) as the cause of PNN changes: (1) CNO was ineffective in hM3Dq-expressing mice; (2) CNO induced PNN regression in the hM4Diexpressing hemicortex but not contralaterally; (3) CNO and PSEM treatments both effectively reduced PNN around PV interneurons expressing their cognate chemogenetic actuator; and (4) our electrophysiological recordings of acute $\mathrm{CNO}$ effects confirm its efficiency in modulating somatodendritic excitability of DREADD-expressing neurons (Alexander et al., 2009; Krashes et al., 2011; but see Stachniak et al., 2014; Gomez et al., 2017). Hence, the PNN changes we observed stem from specific chemogenetic ligand/actuator interactions eliciting a decrease in excitability of selectively targeted cell types.

\section{$\mathrm{PNN}$ regression is triggered by} decreased activity of PV interneurons, rather than by disinhibition-induced network excitation

Targeted modulation of PV interneurons using hM4Di reinstates visual plasticity in the mouse cortex after closure of the critical period (Kuhlman et al., 2013). Consistent with our working hypothesis, we found that this chemogenetic paradigm induced PNN regression in the adult visual cortex. Several observations indicate that this effect, also obtained on inhibition of PV cells by the chloride channel PSAM-GlyR, was associated with the reduction of the electrical activity of these interneurons. Indeed, acute hM4Di activation reduced the excitability of PV cells in cortical slices, consistent with their reduced responsiveness to visual stimuli in vivo (Kuhlman et al., 2013), and decreased cortical $\gamma$ oscillations, which critically rely on these interneurons' activity (Cardin et al., 2009). Conversely, our EEG recordings showed no evidence for unbalanced network excitation (e.g., epileptiform activities) on targeted inhibition of PV interneurons, and targeted excitation of either glutamatergic neurons or PV interneurons using hM3Dq did not alter PNN density. Hence, our results indicate that PV interneuron silencing, rather than disinhibition-induced network excitation, can lead to adult PNN regression, and that not all network activity changes can trigger this effect. In

$\leftarrow$

neprilysin; Tll1, tolloid-like metallopeptidase; Adamts, A Disintegrin And Metalloprotease with Thrombospondin motif; Prss23, serine protease 23. 
support of this interpretation, a reduction in PV interneuron function has been proposed to underlie the effects of several drugs and of dark exposure on adult PNN density or cortical plasticity (Hensch and Quinlan, 2018). Along this interpretation also, we found that chemogenetic inhibition of excitatory neurons, which presumably reduces the activity of the cortical network including PV cells, similarly resulted in PNN regression. It is noteworthy, however, that the activity of PV interneurons strongly influences that of the local visuocortical network, as evidenced by the decrease in cortical oscillations observed in our EEG recordings. Indeed, PV interneurons receive and feedback onto sensory thalamic inputs, are densely interconnected with excitatory neurons and among one another, and form powerful autapses (Bacci et al., 2003; Kloc and Maffei, 2014; Faini et al., 2018; Wang et al., 2019). Hence, adult PNN regression triggered by inhibition of PV interneurons or excitatory neurons may require changes in synaptic drive and network activity patterns that stem from targeted chemogenetic inhibition, but involve other neural cell types.

\section{Activity-dependent regulation of PNN density in the adult} The accumulation of PNN around PV neurons during the juvenile period of postnatal maturation is known to be activitydependent, and has been suggested to involve both neurons and glia (Hensch, 2005; Dityatev et al., 2007, 2010; Giamanco and Matthews, 2012; Kwok et al., 2012; Hensch and Quinlan, 2018; Testa et al., 2019). Some of the activity-dependent factors that regulate juvenile $\mathrm{PNN}$ accumulation may also be involved in the regulation of adult PNN density. Among these factors, $\mathrm{Ca}^{2+}$ entry through both $\mathrm{Ca}^{2+}$-permeable AMPARs, characteristically expressed in PV interneurons (Geiger et al., 1995; Angulo et al., 1997) and L-type voltage-gated $\mathrm{Ca}^{2+}$ channels, is required for juvenile PNN accumulation (Dityatev et al., 2007). Both conductances control $\mathrm{Ca}^{2+}$ entry into PV interneurons (Goldberg et al., 2003a, 2003b), which is thus likely to decrease on chemogenetic inhibition of excitatory neurons (because of reduced excitatory drive onto $\mathrm{PV}$ cells) or of PV neurons (as assessed by their reduced $\mathrm{Ca}^{2+}$ responses to visual inputs in vivo) (Kuhlman et al., 2013). Decreased $\mathrm{Ca}^{2+}$ entry into PV neurons may thus trigger the contribution of these cells to PNN regression in the adult. Yet, a change of OTX2 import in PV interneurons, which controls juvenile PNN accumulation, may also contribute to adult PNN regression in our experimental conditions. Indeed, OTX2 accumulation in PV interneurons is activity-dependent, and the reduction of OTX2 import in the adult induces PNN regression and reinstates juvenile plasticity (Sugiyama et al., 2008; Beurdeley et al., 2012). In addition to PV neurons, our targeted chemogenetic inhibition paradigms likely change the activity of multiple cortical cell types via network effects because of modifications of synaptic drive and/or population synchrony. Glial and neuronal cell types other than PV neurons may thus critically contribute to activity-dependent PNN regulation in the adult, as reported for glial cells in the control of juvenile PNN accumulation (Giamanco and Matthews, 2012). Hence, PNN regulation in the adult may involve some of the activity-dependent mechanisms that regulate juvenile PNN accumulation.

\section{PNNs may be regulated individually in the adult}

The present study provides evidence for the activity-dependent regulation of individual PNNs independently of their neighbors. The possibility that PV interneurons can directly contribute to this process is substantiated by the present analysis of earlier single-cell transcriptomic data (Tasic et al., 2018). Indeed, we confirmed that individual PV cells express many of the essential PNN lecticans and linkers, as well as membrane and secreted proteases (Okaty et al., 2009; Dityatev et al., 2010; Kwok et al., 2012; FerrerFerrer and Dityatev, 2018), including established proteoglycanases (Kelwick et al., 2015); and may thus modulate the density of their own PNN. Indeed, post-translational maturation of proteoglycans by $\mathrm{PV}$ cells has been shown to control PNN density (Miyata et al., 2012). Likewise, activity-dependent modifications in the expression, maturation, or exocytosis of PNN constituents or proteases by adult PV cells may change the synthesis or degradation rate, and thus the density of their PNN. Activity-dependent transcriptional changes in PNN-related genes observed around the juvenile period of PNN formation (McRae et al., 2007; Carulli et al., 2010; Giamanco and Matthews, 2012; Gunner et al., 2019) are unlikely to account for the possible contribution of PV neurons to adult PNN regulation. Indeed, transient silencing of mature PV interneurons for $48 \mathrm{~h}$ does not induce large modifications of their transcriptome, except for genes involved in protein transport (Miller et al., 2011). This suggests that the activity-dependent contribution of PV cells to adult PNN regulation may result primarily from modification in the cellular trafficking of PNN constituents or PNN proteases. Alternatively, adult PNN regulation may rely on activity-dependent changes in the supply of some PNN constituents or proteases by other cell types (e.g., Neurocan or ADAM and Mmp9 proteases from excitatory neurons, or PNN linkers Hapln1 and Ptprz1 from astrocytes).

Multiple earlier studies indicate that PNN removal renders adult cortical network permissive for high circuit plasticity. The targeted chemogenetic paradigm used in the present study is known to reinstate visual plasticity in the young adult after closure of the critical period (Kuhlman et al., 2013). Our results thus raise the possibility that adult PV neurons may contribute to the local regulation of PNN-dependent plasticity, and thereby to the point-by-point tuning of cortical network properties in the adult.

\section{References}

Alexander GM, Rogan SC, Abbas AI, Armbruster BN, Pei Y, Allen JA, Nonneman RJ, Hartmann J, Moy SS, Nicolelis MA, McNamara JO, Roth BL (2009) Remote control of neuronal activity in transgenic mice expressing evolved G protein-coupled receptors. Neuron 63:27-39.

Angulo MC, Lambolez B, Audinat E, Hestrin S, Rossier J (1997) Subunit composition, kinetic, and permeation properties of AMPA receptors in single neocortical nonpyramidal cells. J Neurosci 17:6685-6696.

Angulo MC, Staiger JF, Rossier J, Audinat E (1999) Developmental synaptic changes increase the range of integrative capabilities of an identified excitatory neocortical connection. J Neurosci 19:1566-1576.

Ascoli GA, Alonso-Nanclares L, Anderson SA, Barrionuevo G, BenavidesPiccione R, Burkhalter A, Buzsáki G, Cauli B, Defelipe J, Fairén A, Feldmeyer D, Fishell G, Fregnac Y, Freund TF, Gardner D, Gardner EP, Goldberg JH, Helmstaedter M, Hestrin S, Karube F, et al. (2008) Petilla terminology: nomenclature of features of GABAergic interneurons of the cerebral cortex. Nat Rev Neurosci 9:557-568.

Beurdeley M, Spatazza J, Lee HH, Sugiyama S, Bernard C, Di Nardo AA, Hensch TK, Prochiantz A (2012) Otx2 binding to perineuronal nets persistently regulates plasticity in the mature visual cortex. J Neurosci 32:9429-9437. 
Bacci A, Huguenard JR, Prince DA (2003) Functional autaptic neurotransmission in fast-spiking interneurons: a novel form of feedback inhibition in the neocortex. J Neurosci 23:859-866.

Cardin JA, Carlén M, Meletis K, Knoblich U, Zhang F, Deisseroth K, Tsai LH, Moore CI (2009) Driving fast-spiking cells induces gamma rhythm and controls sensory responses. Nature 459:663-667.

Carulli D, Pizzorusso T, Kwok JC, Putignano E, Poli A, Forostyak S, Andrews MR, Deepa SS, Glant TT, Fawcett JW (2010) Animals lacking link protein have attenuated perineuronal nets and persistent plasticity. Brain 133:2331-2347.

Cauli B, Audinat E, Lambolez B, Angulo MC, Ropert N, Tsuzuki K, Hestrin S, Rossier J (1997) Molecular and physiological diversity of cortical nonpyramidal cells. J Neurosci 17:3894-3906.

Connors BW, Gutnick MJ (1990) Intrinsic firing patterns of diverse neocortical neurons. Trends Neurosci 13:99-104.

Dityatev A, Brückner G, Dityateva G, Grosche J, Kleene R, Schachner M (2007) Activity-dependent formation and functions of chondroitin sulfate-rich extracellular matrix of perineuronal nets. Dev Neurobiol 67:570-588.

Dityatev A, Seidenbecher CI, Schachner M (2010) Compartmentalization from the outside: the extracellular matrix and functional microdomains in the brain. Trends Neurosci 33:503-512.

Fagiolini M, Fritschy JM, Löw K, Möhler H, Rudolph U, Hensch TK (2004) Specific GABAA circuits for visual cortical plasticity. Science 303:16811683.

Faini G, Aguirre A, Landi S, Lamers D, Pizzorusso T, Ratto GM, Deleuze C, Bacci A (2018) Perineuronal nets control visual input via thalamic recruitment of cortical PV interneurons. Elife 7:e41520.

Ferrer-Ferrer M, Dityatev A (2018) Shaping synapses by the neural extracellular matrix. Front Neuroanat 12:40.

Geiger JR, Melcher T, Koh DS, Sakmann B, Seeburg PH, Jonas P, Monyer H (1995) Relative abundance of subunit mRNAs determines gating and $\mathrm{Ca}^{2+}$ permeability of AMPA receptors in principal neurons and interneurons in rat CNS. Neuron 15:193-204

Giamanco KA, Matthews RT (2012) Deconstructing the perineuronal net: cellular contributions and molecular composition of the neuronal extracellular matrix. Neuroscience 218:367-384.

Goldberg JH, Tamas G, Yuste R (2003a) $\mathrm{Ca}^{2+}$ imaging of mouse neocortical interneurone dendrites: Ia-type $\mathrm{K}^{+}$channels control action potential backpropagation. J Physiol 551:49-65.

Goldberg JH, Yuste R, Tamas G (2003b) $\mathrm{Ca}^{2+}$ imaging of mouse neocortical interneurone dendrites: contribution of $\mathrm{Ca}^{2+}$-permeable AMPA and NMDA receptors to subthreshold Ca2+dynamics. J Physiol 551:67-78.

Gomez JL, Bonaventura J, Lesniak W, Mathews WB, Sysa-Shah P, Rodriguez LA, Ellis RJ, Richie CT, Harvey BK, Dannals RF, Pomper MG, Bonci A, Michaelides M (2017) Chemogenetics revealed: DREADD occupancy and activation via converted clozapine. Science 357:503-507.

Gorski JA, Talley T, Qiu M, Puelles L, Rubenstein JL, Jones KR (2002) Cortical excitatory neurons and glia, but not GABAergic neurons, are produced in the Emx1-expressing lineage. J Neurosci 22:63096314.

Gunner G, Cheadle L, Johnson KM, Ayata P, Badimon A, Mondo E, Nagy MA, Liu L, Bemiller SM, Kim KW, Lira SA, Lamb BT, Tapper AR, Ransohoff RM, Greenberg ME, Schaefer A, Schafer DP (2019) Sensory lesioning induces microglial synapse elimination via ADAM10 and fractalkine signaling. Nat Neurosci 22:1075-1088.

Harauzov A, Spolidoro M, DiCristo G, De Pasquale R, Cancedda L, Pizzorusso T, Viegi A, Berardi N, Maffei L (2010) Reducing intracortical inhibition in the adult visual cortex promotes ocular dominance plasticity. J Neurosci 30:361-371.

Hay YA, Naudé J, Faure P, Lambolez B (2019) Target interneuron preference in thalamocortical pathways determines the temporal structure of cortical responses. Cereb Cortex 29:2815-2831.

Hensch TK, Fagiolini M, Mataga N, Stryker MP, Baekkeskov S, Kash SF (1998) Local GABA circuit control of experience-dependent plasticity in developing visual cortex. Science 282:1504-1508.

Hensch TK (2005) Critical period plasticity in local cortical circuits. Nat Rev Neurosci 6:877-888.

Hensch TK, Quinlan EM (2018) Critical periods in amblyopia. Visual Neuroscience, 35:E014.
Hippenmeyer S, Vrieseling E, Sigrist M, Portmann T, Laengle C, Ladle DR, Arber S (2005) A developmental switch in the response of DRG neurons to ETS transcription factor signaling. PLoS Biol 3:e159.

Kelwick R, Desanlis I, Wheeler GN, Edwards DR (2015) The ADAMTS (A Disintegrin and Metalloproteinase with Thrombospondin motifs) family. Genome Biol 16:113.

Kloc ML, Maffei A (2014) Cell type-specific properties of thalamocortical inputs in rodent primary visual cortex. J Neurosci 34:1345513465.

Krashes MJ, Koda S, Ye C, Rogan SC, Adams AC, Cusher DS, MaratosFlier E, Roth BL, Lowell BB (2011) Rapid, reversible activation of AgRP neurons drives feeding behavior in mice. J Clin Invest 121:1424-1428.

Kruglikov I, Rudy B (2008) Perisomatic GABA release and thalamocortical integration onto neocortical excitatory cells are regulated by neuromodulators. Neuron 58:911-924.

Kuhlman SJ, Olivas ND, Tring E, Ikrar T, Xu X, Trachtenberg JT (2013) A disinhibitory microcircuit initiates critical period plasticity in the visual cortex. Nature 501:543-546.

Kwok JC, Warren P, Fawcett JW (2012) Chondroitin sulfate: a key molecule in the brain matrix. Int J Biochem Cell Biol 44:582-586.

Lee HH, Bernard C, Ye Z, Acampora D, Simeone A, Prochiantz A, Di Nardo AA, Hensch TK (2017) Genetic Otx2 mis-localization delays critical period plasticity across brain regions. Mol Psychiatry 22:680688 .

Lensjø KK, Lepperød ME, Dick G, Hafting T, Fyhn M (2017a) Removal of perineuronal nets unlocks juvenile plasticity through network mechanisms of decreased inhibition and increased gamma activity. J Neurosci 37:1269-1283.

Lensjø KK, Christensen AC, Tennøe S, Fyhn M, Hafting T (2017b) Differential expression and cell type specificity of perineuronal nets in hippocampus, medial entorhinal cortex, and visual cortex examined in the rat and mouse. eNeuro 4:ENEURO.0379-16.2017.

Magnus CJ, Lee PH, Atasoy D, Su HH, Looger LL, Sternson SM (2011) Chemical and genetic engineering of selective ion channel-ligand interactions. Science 333:1292-1296.

Maurel P, Rauch U, Flad M, Margolis RK, Margolis RU (1994) Phosphacan, a chondroitin sulfate proteoglycan of brain that interacts with neurons and neural cell-adhesion molecules, is an extracellular variant of a receptor-type protein tyrosine phosphatase. Proc Natl Acad Sci USA 91:25122516.

McRae PA, Rocco MM, Kelly G, Brumberg JC, Matthews RT (2007) Sensory deprivation alters aggrecan and perineuronal net expression in the mouse barrel cortex. J Neurosci 27:5405-5413.

Miller MN, Okaty BW, Kato S, Nelson SB (2011) Activity-dependent changes in the firing properties of neocortical fast-spiking interneurons in the absence of large changes in gene expression. Dev Neurobiol 71:62-70.

Miyata S, Komatsu Y, Yoshimura Y, Taya C, Kitagawa H (2012) Persistent cortical plasticity by upregulation of chondroitin 6-sulfation. Nat Neurosci 15:414-422.

Okaty BW, Miller MN, Sugino K, Hempel CM, Nelson SB (2009) Transcriptional and electrophysiological maturation of neocortical fastspiking GABAergic interneurons. J Neurosci 29:7040-7052.

Paxinos G, Franklin KB (2004) The mouse brain in stereotaxic coordinates. San Diego: Academic.

Pizzorusso T, Medini P, Berardi N, Chierzi S, Fawcett JW, Maffei L (2002) Reactivation of ocular dominance plasticity in the adult visual cortex. Science 298:1248-1251.

Rossier J, Bernard A, Cabungcal JH, Perrenoud Q, Savoye A, Gallopin T, Hawrylycz M, Cuénod M, Do K, Urban A, Lein ES (2015) Cortical fastspiking parvalbumin interneurons enwrapped in the perineuronal net express the metallopeptidases Adamts8, Adamts15 and Neprilysin. Mol Psychiatry 20:154-161.

Rudy B, Fishell G, Lee S, Hjerling-Leffler J (2011) Three groups of interneurons account for nearly $100 \%$ of neocortical GABAergic neurons. Dev Neurobiol 71:45-61.

Sale A, Berardi N, Spolidoro M, Baroncelli L, Maffei L (2010) GABAergic inhibition in visual cortical plasticity. Front Cell Neurosci 4:10

Sieu LA, Bergel A, Tiran E, Deffieux T, Pernot M, Gennisson JL, Tanter M, Cohen I (2015) EEG and functional ultrasound imaging in mobile rats. Nat Methods 12:831-834. 
Stachniak TJ, Ghosh A, Sternson SM (2014) Chemogenetic synaptic silencing of neural circuits localizes a hypothalamus $\rightarrow$ midbrain pathway for feeding behavior. Neuron 82:797-808.

Sugiyama S, Di Nardo AA, Aizawa S, Matsuo I, Volovitch M, Prochiantz A, Hensch TK (2008) Experience-dependent transfer of Otx2 homeoprotein into the visual cortex activates postnatal plasticity. Cell 134:508-520.

Tasic B, Yao Z, Graybuck LT, Smith KA, Nguyen TN, Bertagnolli D, Goldy J, Garren E, Economo MN, Viswanathan S, Penn O, Bakken T, Menon V, Miller J, Fong O, Hirokawa KE, Lathia K, Rimorin C, Tieu M, Larsen R, et al. (2018) Shared and distinct transcriptomic cell types across neocortical areas. Nature 563:72-78.
Testa D, Prochiantz A, Di Nardo AA (2019) Perineuronal nets in brain physiology and disease. Semin Cell Dev Biol 89:125-135.

Ueno H, Takao K, Suemitsu S, Murakami S, Kitamura N, Wani K, Okamoto M, Aoki S, Ishihara T (2018) Age-dependent and region-specific alteration of parvalbumin neurons and perineuronal nets in the mouse cerebral cortex. Neurochem Int 112:59-70.

Wang L, Kloc M, Maher E, Erisir A, Maffei A (2019) Presynaptic GABAA receptors modulate thalamocortical inputs in layer 4 of Rat V1. Cereb Cortex 29:921-936.

Ye Q, Miao QL (2013) Experience-dependent development of perineuronal nets and chondroitin sulfate proteoglycan receptors in mouse visual cortex. Matrix Biol 32:352-363. 